\title{
Life Cycle Assessment on the use of Ultra High Performance Fibre Reinforced Concretes with enhanced durability for structures in extremely aggressive environments: case study analyses
}

\author{
M.C. Caruso ${ }^{1}$, C. Pascale ${ }^{1}$, E.Camacho ${ }^{2}$, S. Scalari ${ }^{3}$, F. Animato ${ }^{3}$, M.C. Alonso ${ }^{4}$, M. Gimenez ${ }^{4}$, \\ L. Ferrara ${ }^{5}$ \\ ${ }^{1}$ Sviluppo Tecnologie e Ricerca per l'Edilizia Sismicamente Sicura ed Ecosostenibile S.c.ar.l. \\ (STRESS), Vico II S. Nicola alla Dogana, 80133, Napoli (Italy) \\ ${ }^{2}$ Research \& Development Concretes SL (RDC), Conde De Altea 52-3, 46005, Valencia (Spain) \\ ${ }^{3}$ Enel Green Power (EGP), Viale Regina Margherita, 125, 00198, Roma (Italy) \\ ${ }^{4}$ Instituto Eduardo Torroja - Consejo Superior de Investigaciones Científicas (CSIC), Calle de \\ Serrano Galvache, 4, 28033, Madrid, (Spain) \\ ${ }^{5}$ Politecnico di Milano, Piazza Leonardo da Vinci 32, 20133, Milano (Italy)
}

Keywords: Ultra-High Durability Concrete, Comparative Life-Cycle Assessment, Structural durability, Aggressive environment, Concrete infrastructures

\section{INTRODUCTION}

Last decades have been characterized by growing attention on sustainable development. The European Commission interest in this topic is evident considering the global agreements and the related massive investments that have been, and still are, carried out to guarantee a sustainable approach to global growth. A contribution to pursue this challenging goal is provided by the EUfunded ReSHEALience Project (GA n ${ }^{\circ}$ 760824). ReSHEALience Project aims at developing Ultra High Performance Fibre Reinforced Concretes with enhanced durability (Ultra High Durability Concrete - UHDC) that will be characterized by at least $30 \%$ longer service life as compared to traditional concretes. The increase of durability will be analyzed also from a sustainability point of view taking into account all the environmental, economic and social impacts, associated to the longer life-cycle of the structures.

In this paper, comparative environmental analyses of traditional and innovative solutions for infrastructures exposed to extremely aggressive environments are presented.

In detail, the first analyzed case study deals with off-shore aquaculture rafts exposed to marine environments (XS); whilst the second case study concerns basins for collection of cooling tower water in geothermal power plants, exposed to chemical attack (XA). The analyzed off-shore aquaculture rafts are located in Spain and used for farming mussels or other mollusks, supporting 70tons of harvest. Traditionally these rafts are made of wooden primary and secondary beams, connected with steel nails. Wooden beams can last up to 15 years and are subjected to continuous maintenance, such as paint protection or beams replacement. Moreover, bolt (re)screwing and inspections are often needed. The aquaculture raft solution studied is based on the design launched in 2015 by the company RDC, made with Ultra-High Performance Concrete (UHPC). Here, the study is done using proposing Ultra High Durability Concrete (UHDC). The mix design for $1 \mathrm{~m}^{3}$ of this material includes $800 \mathrm{~kg}$ of cement, $1062 \mathrm{~kg}$ of siliceous sand, $175 \mathrm{~kg}$ of silica fume, $30 \mathrm{~kg}$ of superplasticizer, $160 \mathrm{~kg}$ of steel fibers as reinforcement and $0.8 \%$ of 
cement weight of crystalline self-healing stimulating admixture (Penetron ADMIX ${ }^{\circledR}$ ); w/c ratio is equal to 0,2. UHDC beams do not need maintenance during all their life, which has been assumed at least equal to 50 years. The analyzed cooling tower water basin is located in Chiusdino, Italy, close to a geothermal plant, owned by Enel Green Power (EGP). Traditional solutions are made of conventional concrete, with Ordinary Portland Cement (OPC). Due to chemical attack, traditional basins, whose walls can be as thick as $400 \mathrm{~mm}$, can last up to 20 years; moreover, they need maintenance about every 5 years, mainly due to concrete and waterproof coatings degradation. Two alternative solutions for innovative water basins are herein considered, as a preliminary design, having different geometry: INN1, with $300 \mathrm{~mm}$ walls; INN2 with $200 \mathrm{~mm}$ walls and buttresses. Innovative water basins are made of Ultra High Durability Concrete (UHDC): the mix design of $1 \mathrm{~m}^{3}$ of INN1 concrete includes: $600 \mathrm{~kg}$ of Portland Cement, $982 \mathrm{~kg}$ of sand, $33 \mathrm{l}$ of superplasticizer, $500 \mathrm{~kg}$ of slag, $120 \mathrm{~kg}$ of steel fibers as the sole reinforcement, and $0.8 \%$ of cement weight of crystalline self-healing stimulator Penetron $\mathrm{ADMIX}^{\circledR}$, and a w/c ratio equal to 0,33 ; the mix design of $1 \mathrm{~m}^{3}$ of INN2 concrete is similar to INN1, but also includes $0.25 \%$ of cement weight of alumina nanofibers for enhanced durability $\left(10 \%\right.$ dispersion of $\mathrm{NAFEN}^{\circledR}$ ). Innovative water basins can last 50 years; moreover, they require less maintenance activities.

For both case studies, a reference unit, the so-called "Functional Unit (FU)", is set, together with the life-cycle phases of traditional and innovative structures to be compared, in order to assure the functional equivalence between the analyzed solutions. Environmental impacts of the alternative solutions of the analyzed case studies are compared according to Life-Cycle Assessment (LCA) standards (ISO 14040:2006 [1] and 14044:2006 [2]) and performed with the European EPD 2013 (Environmental Product Declaration) method [3] for Life Cycle Impact Assessment (LCIA). Results are reported in percentage terms in order to show the comparison between the impacts of alternative solutions.

\section{LIFE CYCLE ASSESSMENT STUDY AND RESULTS}

According to LCA standards, the FU and the System Boundary of infrastructures to be compared are defined. System Boundary is set according to the EN 15804 [4], as reported in Figure 1.

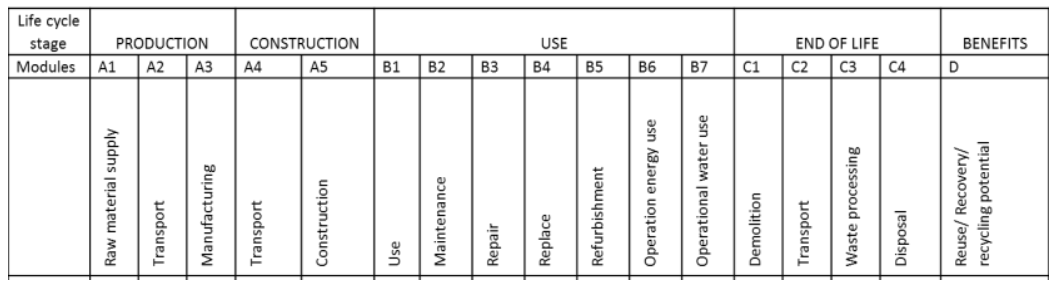

Figure 1. Life Cycle stages for construction products - EN 15804 [4]

Then, the data collection of all inputs and outputs related to each stage of the infrastructures life cycle is performed in order to realize the Inventory that is necessary for LCIA. This has been performing using the SimaPro 9.0 [5] software. Comparative environmental results are then provided in terms of the following environmental categories: Acidification; Eutrophication; Global warming; Photochemical oxidation; Ozone layer depletion; Abiotic depletion; Abiotic depletion, fossil fuels.

In the following, the comparative LCA study and related results are provided for the off-shore aquaculture rafts and the cooling tower water basins. 
Off-shore aquaculture raft

A comparison between a traditional and an innovative off-shore aquaculture raft is here performed. The FU is "the whole mussel raft, used for the production of 70t of mussels in marine environment". The System Boundary includes the following phases according to EN 15804:

- production (modules A1-A2-A3), transport from the manufacturing to the building site (A4) and raft installation (A5);

- maintenance operation considering a lifetime of 50 years (B2). It should be noticed that the lifetime of a wooden raft is 15 years, while the lifetime of a UHDC raft has been set to 50 years. In order to compare both solutions, a lifetime of 50 years is considered; this means that for the wooden raft, maintenance operations until 50 years have been considered

- deconstruction of the raft $(\mathrm{C} 1)$, transport of the raft to the landfill site or the recycling plant (module C2), waste processing of steel components (C3) as well as reuse of the wooden components of raft (Module D).

Moreover, two maintenance options are considered for the traditional raft: Option 1, in which the substitution of primary and secondary beams and relative connections is made with manual operations (every year approximately $4 \mathrm{t}$ of wood are substituted); Option 2 , in which protective paint is applied (paint is applied each year during the first 3 years, later it is not painted until year 6 , when it is painted again every year until the end of its lifetime).

Figure 2a shows that the highest environmental impacts are caused by the traditional raft when paint protection is choosen as a maintenance option. For 4 out of 7 impact categories (Acidification, Global Warming, Ozone Layer Depletion and Abiotic Depletion, fossil), the traditional raft, in case logs replacement is choosen as maintenance, provides the lowest impacts; for 3 out of 7 impact categories (Eutrophication, Photochemical Oxidation and Abiotic Depletion), the innovative raft provides the lowest impacts. Considering Option 2 maintenance, environmental impact reduction of innovative solution varies from $28 \%$ in case of Ozone Layer Depletion to $87 \%$ in case of Acidification.

\section{Cooling Tower Water Basin}

A comparison between a traditional and two innovative concrete cooling tower water basins is here performed. The FU is "whole water collection basin of the cooling tower, designed for containing the same amount of water flow". The System Boundary includes the following phases according to EN 15804:

- production (modules A1-A2-A3), and construction of the (A4-A5) considering that the elements may be precast on site (the only kind of transport considered is transport of raw material to construction site);

- repair of basin components, considering a lifetime of 50 years (B3);

- demolition of the basins (C1), transport of the materials to the landfill site or the recycling plant (module C2), concrete waste processing (C3), disposal of basin components (C4) as well as recycling of the basin concrete (D).

Figure $2 \mathrm{~b}$ shows that the highest environmental impacts are caused by the traditional water basin. Environmental impacts of INN1 and INN2 are very similar, leading to an environmental reduction varying from $11 \%$ in case of Eutrophication, to $71 \%$ in case of Abiotic Depletion. 


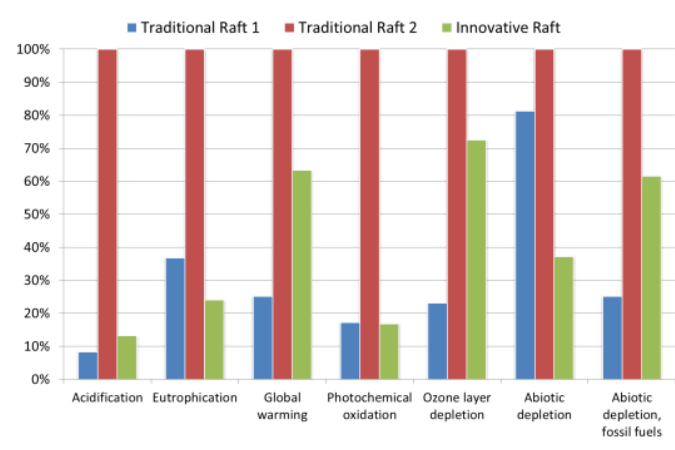

a)

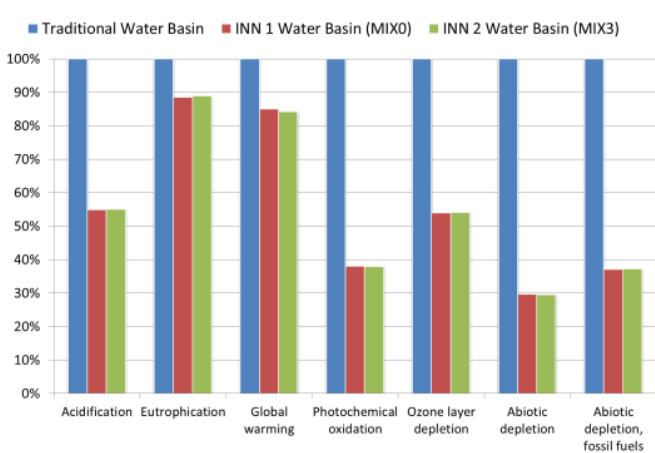

b)

Figure 2. a) Comparative LCA of the Off-shore aquaculture raft; b) Comparative LCA of the Cooling tower water basin

\section{CONCLUSIONS}

The paper focuses on the assessment of environmental impacts related to the life cycle of infrastructures exposed to extremely aggressive environments. The LCA study performed between traditional and innovative solutions (the latter realized with Ultra High Durability Concrete materials conceived and tested in the framework of the activities of the H2020 ReSHEALience project) highlights the better performances of the latter in environmental terms. In particular, when comparing traditional and innovative concrete solutions (Cooling tower water basins), the innovative UHDC ones always show a whole better environmental performance; whilst the comparison of wooden solutions with UHDC ones (Off-shore aquaculture rafts) highlights the good performance of the innovative concrete mainly due to its increased durability and thus longer lifetime. Future developments will include the addition of economic and social performances for sustainability assessment.

\section{ACKNOWLEDGEMENT}

The activity described in this paper has been performed in the framework of the project "Rethinking coastal defence and Green-energy Service infrastructures through enHancEddurAbiLity high-performance cement-based materials-ReSHEALience", funded by the European Union Horizon 2020 research and innovation programme under GA No 760824. The authors also acknowledge Enrico Gastaldo and Valentina Violante from PENETRON Italy, and Alexey Tretjakov and Denis Lizunov from ANF Development for helping in collecting data on PENETRON ADMIX ${ }^{\circledR}$ and NAFEN ${ }^{\circledR}$ alumina nanofibers, respectively.

\section{REFERENCES}

1. International Standards Organisation, ISO 14040:2006, Environmental management - Life cycle assessment - Principles and framework, Brussels: CEN (European Committee for Standardisation), 2006.

2. International Standards Organisation, ISO 14044:2006, Environmental management - Life cycle assessment - Requirements and guidelines, Brussels: CEN (European Committee for Standardisation), 2006

3. EPD International (2013) General Programme Instructions of the International EPD® System. Version 2.01, dated 2013-09-18

4. EN 15804:2012+A1:2013, Sustainability of construction works - Environmental product declarations - Core rules for the product category of construction products

5. PRé - Goedkoop M., Oele M., Leijting J., Ponsioen T., Meijer E. "Introduction to LCA with SimaPro" v.5.2 - January 2016 